\title{
Optics and photonics education centers of excellence: an opportunity for international collaboration
}

Daniel Hull

Daniel M. Hull, "Optics and photonics education centers of excellence: an opportunity for international collaboration," Proc. SPIE 9793, Education and Training in Optics and Photonics: ETOP 2015, 97930A (8 October 2015); doi: $10.1117 / 12.2223058$

Event: Education and Training in Optics and Photonics: ETOP 2015, 2015, Bordeaux, France 


\title{
Optics and Photonics Education Centers of Excellence: An Opportunity for International Collaboration \\ Daniel M. Hull \\ The National Center for Optics and Photonics Education \\ OP-TEC/University of Central Florida, 316 Kelly Drive, Waco TX, 76710
}

\begin{abstract}
The increased demand for highly educated and trained workers in optics and photonics is evident in many countries. Colleges and universities that provide this education can benefit greatly from support by non-profit National Education Centers of Excellence that conduct research in workforce needs, design curricula, develop industry-validated teaching materials, train new faculty and establish models for laser/optics laboratories.

In 2006, the National Science Foundation (NSF) established OP-TEC, the National Center for Optics and Photonics Education, which encourages and supports U.S. colleges to educate and train an adequate supply of high quality technicians to meet the workforce demand by companies, institutions and government agencies.

In 2013 and 2014 NSF awarded grants to establish regional photonics centers in the southeast U.S. (LASER-TEC) and the Midwest (MPEC). These Centers work cooperatively with OP-TEC, sharing resources, teaching materials and best practices for colleges with photonics technician education programs. This successful "center organization plan" that has evolved could be adopted in other countries, and international cooperation could be established between similar Centers of Education in Photonics education.
\end{abstract}

Key Words: photonics technician education, precision optics technician education, lasers, curriculum, courses, NSF/ATE courses

\subsection{INTRODUCTION}

The National Center for Optics and Photonics Education (OP-TEC), an organization of the University of Central Florida, is completing its ninth year of operation, funded by a grant from the Advanced Technological Education division of the U.S. National Science Foundation. www.op-tec.org

The mission of OP-TEC is to increase the supply of well-educated photonics technicians by building and strengthening the capacity and quality of photonics education in U.S. two-year colleges. OP-TEC provides sub grants to colleges with wellestablished photonics technician programs. These "Partner Colleges" provide models for other colleges to emulate; faculty at the Partner Colleges also assist OP-TEC staff in providing technical assistance to other colleges.

In the past two years OP-TEC has encouraged two Partner Colleges (Indian River State College FL, and Indian Hills Community College IA) to organize regional photonics clusters of colleges and employers', and assisted them to apply and receive NSF/ATE grants to become Regional Centers for Optics and Photonics Education. The regional centers work closely with OP-TEC to complement its work with colleges in the U.S.

The regional centers are responsible for assisting colleges with photonics programs in their region of the U.S. Each regional center is also responsible for curriculum, professional development and teaching materials for specific fields and applications 
of optics and photonics. The cooperative effort between the national and the regional centers has eliminated duplication of materials and services and greatly expanded the influence and quality of support to the colleges teaching optics and lasers.

\subsection{The Role of National and Regional Optics and Photonics Centers}

The responsibilities, activities and accomplishments of OP-TEC are organized around five major goals:

1. Serve as the leader of the U.S. network of colleges and employers offering optics and photonics technician education.

- OP-TEC has worked with over 200 employers to develop the National Skill Standards for Photonics Technicians ${ }^{1}$. These skill standards, which are updated every 3-5 years, form the basis for the design of curricula, courses and teaching materials for Photonics Systems Technicians.

- OP-TEC has worked with over 50 employers and the American Precision Optics Manufacturers Association to develop the national Skill standards for Precision Optics Technicians, which form the basis for the design of the curriculum, courses and teaching materials for Precision Optics Technicians ${ }^{2}$.

- OP-TEC sponsored research to assess the current and future demand for Photonics Technicians and Precision Optics Technicians. In the next several years over 800 new photonics technicians and 200 new precision optics technicians will be needed in the U.S. ${ }^{3}$

- OP-TEC collects data from U.S. colleges to determine photonics student enrollment and completers. Currently the 35 colleges are producing over 300 new photonics technicians each year; far short of the demand.

- The OP-TEC Photonics College Network (OPCN) was organized to facilitate the 35 U.S. colleges teaching photonics to share resources, innovations and best practices through teleconferences, webinars and annual meetings

- Organize and expand the Photonics Technician Alumni Council (PACT) to provide advice and feedback regarding curriculum content and to provide role models/advice for recruiting new students.

- Cooperate with local colleges to conduct hybrid, on-line course to educate employed technicians ${ }^{4}$.

2. Provide up-to-date, employer-validated resources to improve teaching and learning in optics, lasers and photonics education.

- OP-TEC has created and tested the following teaching materials (including laboratory activities) for programs to educate Photonics Systems Technicians 5 .

$>$ Fundamentals of Light and Lasers (six modules on the nature of light, geometrical and wave optics, laser operation and laser safety) ${ }^{6}$.

$>$ Laser Systems and Applications (ten modules on intercavity modulation, measurement of laser output, studies of six laser types, troubleshooting and systems integration ${ }^{7}$.

$>$ Ten Photonics-Enabled Technology modules, teaching the applications of lasers in health care, manufacturing, defense/aerospace, manufacturing, energy etc ${ }^{8}$.

- OP-TEC has created and is testing the following teaching materials (including laboratory activities) to educate Precision Optics Technicians.

$>$ Quality Assurance for Precision Optics (three modules w/laboratories) ${ }^{9}$.

$>$ Metrology of Optical Systems (three modules w/laboratories) ${ }^{10}$.

- OP-TEC has created Curriculum Planning Guides for Photonics Systems Technicians and Precision Optics Technicians, which include information for teaching, equipment acquisition, laboratory design, lab safety and lab equipment storage/maintenance ${ }^{11}$.

- OP-TEC has created and tested an E-Book for Laser Systems and Applications, which contains mathematics video tutorials, lab introduction videos and concept tutorials using interactive, graphical simulations.

- $\quad$ OP-TEC has created an E-Book entitled Essential Mathematics for Engineering Technicians. 
3. Expand the number of educational courses and programs in optics and photonics offered by colleges and high schools.

- OP-TEC conducts exhibits at national conferences and distributes internet information to inform colleges and faculty about photonics and the opportunity to initiate associate degree educational programs to produce optics and photonics technicians.

- Colleges interested in initiating or strengthening optics and photonics programs are provided information about employers in their service region, as well as technical assistance to design curricula, courses and laboratories. OPTEC also provides guidance on laser safety in the design and operation of high power laser labs.

- OP-TEC funds and supports dedicated student recruiters at 13 colleges. These recruiters conduct community events and provide outreach, information about optics and lasers, as well as career information about photonics technicians and opportunities for career preparation at nearby colleges. The goal is to increase the student enrollment in optics and photonics programs. OP-TEC frequently creates new recruiting materials and disseminates them to the recruiters and in networking teleconferences where they also share best practices in student recruitment.

4. Provide education and training for administrators, counselors, high school teachers, and community college faculty members.

- OP-TEC and its Partner Colleges conduct "Information Workshops" for teachers and administrators of high schools and colleges that are interested in learning more about photonics education opportunities.

- OP-TEC conducts on line training for new optics and photonics instructors. Partner colleges conduct three-day "hands-on" laboratory sessions for faculty who complete the on-line courses.

- OP-TEC conducts extensive professional development for photonics faculty, including networking, webinars and the opportunity to attend a national conference on technical education.

5. Identify and support the emergence of new technologies, including alternative energy, that require technician knowledge and skills in optics and photonics.

- The OP-TEC staff, as well as faculty at Partner Colleges, examine technical literature and attend conferences to learn of emerging applications in optics and photonics that should be introduced to photonics faculty or added to existing courses.

- This information is provided to photonics faculty in the form of news briefings, internet references and webinars. Recent examples include fiber lasers, vertical cavity surface emitting lasers etc.

- OP-TEC is providing assistance and advice for workforce development to support innovations in silicon photonics.

\subsection{Cooperation and Collaboration Among Optics and Photonics Education Centers}

In the last two years two NSF Regional Photonics Centers have been created to work cooperatively with OP-TEC in support of colleges with photonics programs.

- LASER TEC, the Southeast U.S. Regional Center in Optics and Photonics Education, located at Indian River State College FL, serving colleges in eight Southeast states, and specializing in fiber optics communication and spectroscopy. www.laser-tec.org/

- MPEC, the Midwest Photonics Education Center, located at Indian Hills Community College IA, serving colleges in nine Midwest states and specializing in laser materials processing and digital manufacturing. http://www.atecenters.org/engineering-technologies/mpec-midwest-photonics-education-center/

These Regional Centers serve colleges within designated states in their region of the U.S. Each Center also specializes in education for one or two fields of photonics applications, such as fiber optics communication, manufacturing/materials processing and spectroscopy. OP-TEC specializes in the other applications such as biomedical equipment, defense/aerospace, energy production and environmental monitoring. 
Before the regional Centers were created, OP-TEC was responsible for accomplishing all the goals cited in the previous section 2.0. Today, the regional centers support Goal \#1 by tailoring the Skill standards to the collective needs of employers in their region, and work with colleges to tailor their curricula accordingly. The regional centers support Goal 2 by developing teaching materials and providing technical assistance to create courses that are aligned to their designated technical specialty. The regional centers complement OP-TEC in supporting Goal 3 by encouraging colleges in their region to consider offering photonics technician education and by providing technical assistance to colleges that have committed to initiate teaching photonics courses. Regional centers complement OP-TEC in Goal 4 by providing training and professional development in the technical areas that they have committed to support. Regional center support for Goal 5 involves researching and dissemination information/training for emerging applications of optics and photonics in their committed areas. OP-TEC provides this service in other application areas such as biomedical equipment, defense/aerospace, energy production and environmental monitoring.

This cooperation and support among the three centers has resulted in eliminating duplication of efforts and more intensive, higher quality support for photonics technician education in colleges throughout the U.S. OP-TEC is working with lead colleges in the western and northeastern U.S. to create regional clusters and apply for grants as additional regional centers.

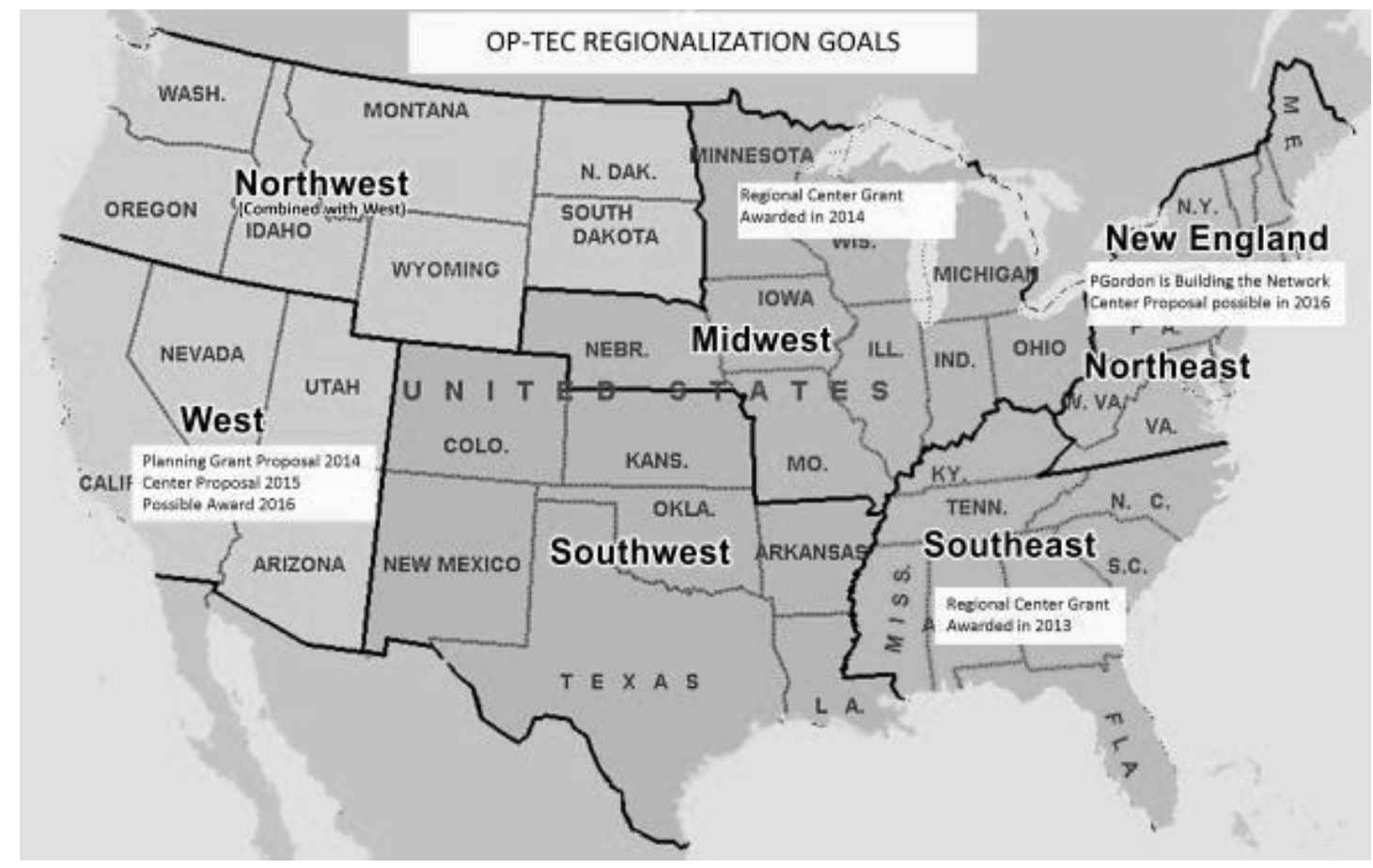

Figure 1. OP-TEC regionalization goals

\subsection{Expanding the Network of Optics and Photonics Education Centers Worldwide}

Other countries are encouraged to examine this model and consider forming similar Centers for international collaboration and cooperation with the U.S. Centers. 


\section{REFERENCES}

[1] OP-TEC, "National Photonics Skill Standards for Technicians, $3^{\text {rd }}$ Edition," University of Central Florida, $<$ http://www.op-tec.org/skill.php>

[2] OP-TEC, "Education and Training for Precision Optics Technicians," University of Central Florida, <http://www.optec.org/precisionoptics.php>

[3] Hull, Darrell; Illich, Paul; Ruggiere, Paul, "Industry Demand for Two-Year College Graduates in Optics and Photonics Technology," OP-TEC, (2012)

[4] Hull, Daniel, "Fueling the Photonics Workforce," The Optical Society. Optics \& Photonics News. Papers 25 (1), 16-18 (2014).

[5] Panayiotou, Dr. Chrys A., "Transforming Electronics Engineering Technology by Infusing Photonics," Indian River State College, 28-31 July 2008.

[6] OP-TEC, "Fundamentals of Light and Lasers," University of Central Florida, <https://www.optecstore.org/products/fundamentals-of-light-and-lasers/>

[7] OP-TEC, "Laser Systems and Applications," University of Central Florida, <https://www.optecstore.org/products/course2-laser-systems-and-applications/>

[8] OP-TEC, "Photonics Enabled Technology Modules," University of Central Florida, <https://www.optecstore.org/product-category/laser-optics-and-photonics-series/pet-modules/>

[9] OP-TEC, "Quality Assurance of Precision Optics," University of Central Florida, <https://www.optecstore.org/products/quality-assurance-of-precision-optics/>

[10] OP-TEC, "Metrology of Optical Systems," University of Central Florida. <https:optecstore.org>

[11] OP-TEC, "Photonics Systems Technician Curriculum Guide," University of Central Florida, $<$ https://www.optecstore.org/products/curriculum-guide/> 